\title{
Letters
}

Website: bmj.com

Email: letters@bmj.com

\section{More on the consultant contract}

Framework doesn't consider anomaly of $£ 100000$ in lost earnings for some

EDITOR-Like most correspondents, I am filled with a mixture of disbelief and horror about the proposed new consultant contract. ${ }^{1}$ At a recent BMA meeting in Leeds the audience did not leave "reassured and ready to spread the word" like those described by our chief negotiator, Peter Hawker, in the press release of 8 July. The general mood was one of disappointment and at times open hostility. Several points arose which have not been addressed in the correspondence-here are two.

Firstly, the new contract contains an iniquitous anomaly affecting consultants recently appointed at the bottom of the existing pay scale. This is not included in any BMA document. Under the new framework, existing consultants appointed at the top of the pay scale will receive five years of seniority credit in comparison with those appointed on exactly the same date at the bottom of the scale. In the current contract those who start on minimum salary take five years to achieve parity of pay. Under the new contract it will take 20 years. For consultants recently appointed at minimum salary this equates to lost earnings in excess of

\section{Advice to authors}

We prefer to receive all responses electronically, sent directly to our website. Processing your letter will be delayed unless it arrives in an electronic form.

We are now posting all direct submissions to our website within 24 hours of receipt and our intention is to post all other electronic submissions there as well. All responses will be eligible for publication in the paper journal.

Responses should be under 400 words and relate to articles published in the preceding month. They should include $\leqslant 5$ references, in the Vancouver style, including one to the BMJ article to which they relate. We welcome illustrations.

Please supply each author's current appointment and full address, and a phone or fax number or email address for the corresponding author. We ask authors to declare any competing interest. Please send a stamped addressed envelope if you would like to know whether your letter has been accepted or rejected.

Letters will be edited and may be shortened.

bmj.com

letters@bmj.com
$£ 100$ 000. Appointments to top scale are rarely made on the basis of experience or merit but are commonplace where posts are difficult to fill-this is blatant discrimination against those of us appointed on minimum salary.

Secondly, the BMA reassures us that regular evening and weekend sessions are unlikely to become the norm because of the difficulty in finding non-medical staff to support them. It seems blindingly obvious to everyone except our negotiators that this is the cheapest way for the government to deliver a $50 \%$ increase in outpatient and operating theatre capacity. Our new outpatient manager pointed this out to me four months ago: she would have no difficulty in recruiting nurses for evening clinics but conceded that consultants would prove a much harder obstacle. Cynical consultant would expect the Department of Health to suggest such a move, but it is quite astonishing that the BMA should not just suggest but commend this to us-and at standard rates of pay.

The whole approach of the BMA has been to sell rather than explain this proposal. In the press release of 8 July it even describes the consultation process as the vote yes campaign. The negotiators have clearly had a gruelling two years, and we can conclude only that their apparent enthusiasm for the framework results more from a dread of further negotiations than from a belief that it is a good deal. ${ }^{2}$ We must send them back to renegotiate with a resounding no vote.

Colin J P Welsh consultant physician/cardiologist Huddersfield Royal Infirmary, Huddersfield HD3 3EA

cwelsh@cht.nhs.uk

1 Correspondence. Consultants' new contract. $B M$ 2002;325:99. (13 July.)

2 Hargreaves S. Government makes U turn on private practice ban. BMJ 2002;324:1473. (22 June.)

\section{Consultants are at risk of losing both} independence and democratic rights

EDITOR-The BMA has promised to put the proposed new consultant contract to the vote by consultants and specialists registrars, members and non-members.

Recently, both Peter Hawker, chairman of the Consultants and Specialists Committee, and John Hutton, health minister, have said that the contract is not renegotiable if the vote is negative. Why then have a vote? I detect echoes of the democratic vote in the Reichstag when Hitler ensured that he was returned as chancellor.

Briefings have been circulated to trusts by the NHS Executive which instruct chief executives how to proceed with implementing the new contract from April 2003. There is no mention of the doctors' vote or what happens in the event of rejection.

I doubt that I am in the minority in suspecting that the opinion of the consultants is of no consequence and the contract will proceed whatever the result of our vote. We are to lose both independence and democratic rights.

N E Cetti consultant urologist

Queen Elizabeth Hospital, London SE18 4QH

\section{Consultants should assess the detail of new contract}

EDITOR-The negotiations for the new consultant contract have been difficult and protracted. The outcome is, as agreed by our negotiators, a compromise. Those who have suggested that the new contract is a sell out have not thought through the detail. The contract is work sensitive, recognising time spent on administration, teaching, training, audit, and other extra-patient activities.

The deal is not as good as the junior doctors negotiated. However, we as consultants currently have an open ended contract that is not in our interests. Our working conditions are increasingly open to management manipulation; job plans are likely to be increasingly enforced. If so, we might as well be recompensed. We may end up clocking in and clocking out, so let's tie the employer down.

All the talk of enforced working until $10 \mathrm{pm}$ and midday on Saturday is poppycock. Nobody will be forced: it will depend on local negotiation. Given the logistics of running an outpatient clinic until $10 \mathrm{pm}$, staff are unlikely to be available unless they are adequately paid. The proposed contract would be based on a 40 hour week, of which 28 hours would usually be spent on direct clinical care. Most consultants do more than this now, without recognition. So, what is the problem?

A fear that we may be more accountable? That is going to come anyway.

Our professional lives may become less flexible? Not if you look at the detail. Some of my colleagues have argued that this is a geographical contract: those in the north of the country with little private practice will vote yes while those in the south will say no. In fact, private practice is not the issue, except for the few who perhaps do not currently meet their NHS obligations. I suggest 
that those who have "shot from the hip" think again. I am 58 and intend to retire at 60 , so I am least likely to benefit from the proposed contract (the assimilation deal is not very good).

I believe that the contract represents a good deal. If we reject it we are back to square one. In the meantime, managers would most likely invoke the powers they already have to nail our feet to the floor. I suggest that every consultant look at their current working life and work out what they are worth now and what they would be worth if the new contract were to be introduced.

JS is chairman of the Surgical Specialties Subcommittee of the Consultants and Specialists Committee. This letter describes his views and not those of the committee. He has been well informed about the BMA's negotiations but has not been involved in the process.

John Storrs consultant maxillofacial surgeon

Canterbury CT3 1NG

storrs@supanet.com

\section{What about consultants in frontline specialties?...}

EDITOR-The framework agreement on the new consultant contract offers little benefit for consultants in frontline specialties such as vascular surgery, obstetrics, intensive care, and paediatrics. An increasing number of such specialties are becoming consultant based, especially for emergency work. This is because of the reduction in junior doctors' hours and the requirement for better supervision of less experienced trainees.

Hawker claims that the inclusion of emergency and on-call work within the 10 session contract is a major advantage. ${ }^{1}$ I see no advantage and believe that there should be separate contracts for elective and emergency work. The maximum of two sessions for unpredictable emergency work (only one until 2005) is woeful-a single complex emergency such as a ruptured aortic aneurysm will consume this. Hawker claims that recognition for the disruption of on-call availability was an important objective for the negotiators. Presumably, they aren't doing on-call in a hard pressed specialty or they would have insisted on more than a maximum supplement of $8 \%$ for work that causes intense disruption of family life. The new contract will also create a paradox that consultants will have to become resident when on-call to have their work properly recognised whereas junior doctors will not.

Junior doctors and staff grade doctors are now paid a proper rate for emergency and on-call work and every hour on-call is an hour worked. Specialists need the same deal: the current junior doctors will certainly view the lack of such an arrangement as a major impediment when they become consultants. Adequate remuneration of such work also allows flexibility for senior consultants who find it increasingly difficult to cope with the rigours of emergency work. Consultants will not be able to opt out of emergency and on-call work because the small amount of money released will not pay for the cost of covering this.

The failure of the negotiators to address these crucial issues will impair the future provision of consultant based emergency care for the NHS as it will create a staffing crisis in frontline specialties. Yes, a pay increase would be nice, but most of us would prefer a better quality of life. What we need are many more consultants to provide such a service. This will cost more than the government would like, which is why we are being offered the carrot of a salary increase to accept the status quo.

In reality, this new contract does not offer a new or creative solution to the problem of emergency and on-call work faced by an increasing number of specialties. I will not support this charter of enslavement, and I urge our negotiators to return to the negotiating table.

Jonathan D Beard consultant vascular surgeon Sheffield Vascular Institute, Northern General Hospital, Sheffield S5 7AU

Jonathan.Beard@sth.nhs.uk

1 Hawker P. New consultant contract marks huge step forward. BMJ 2002:325:334. (10 August)

\section{... And what about the teaching role of consultants?}

EDITOR-The proposed new consultant contract has a number of positive points. ${ }^{1}$ I $\mathrm{am}$, however, concerned that it devalues the teaching role of consultants when this role needs to be increased.

There is to be an unprecedented increase in the number of undergraduate medical students in England and Wales and four new medical schools have been founded. At the same time, rightly or wrongly, the delivery of medical education has shifted from universities to the NHS. This increased load will fall very largely on the consultant body. The alternative, a large scale shift to community based teaching, though perhaps desirable, is unlikely given the recruitment difficulties in general practice.

Soon most hospitals of any size will have a significant number of students on site for much of the year. The need for postgraduate education will increase at least in proportion to the new graduates. Most consultants will need to have their teaching duties as clearly defined as their clinical ones, and they will need to develop an expertise and professionalism commensurate with the importance of the role.

It is therefore disappointing that in the proposed contract teaching duties compete with many others in the two or three sessions designated as supporting professional activities. The focus will probably be on delivering the other seven or eight direct clinical care sessions with everything else pushed into whatever time remains. Extra sessions above 10 are available and may help if consultants want them and managers will pay but they are likely to be out of hours and reinforce the impression that teaching is an optional extra. There is scope for local variation in applying the rules, but this is no sub- stitute for an expectation that teaching receives its due in all cases.

Most consultants will require protected time for teaching to do their job properly. The protection needed is from direct clinical care duties; without it the students will suffer and the quality of the product decline.

John B Cookson consultant physician

University Hospitals of Leicester, Glenfield

Hospital, Leicester LE3 9QP

jackie.phipps@uhl-tr.nhs.uk 1 Correspondence. Consultants' new contract. BMJ
2002;325:99. (13 July.)

\section{Consultants need to take the lead in} using funds for stimulating new ways of working...

EDITOR-The correspondence about the new contract framework shows consultants moaning about the derisory remuneration for being on-call and the lack of additional payments above standard rates for unsocial hours in the evening and at the weekend. ${ }^{1}$ However, these are not unreasonable whinges about a contract framework which, according to the government, should inspire people to deliver a new consumer style NHS offering patient centred care with genuine patient choices while making the most effective use of NHS resources.

The hypocrisy is that both whinging consultants and their BMA leaders are willing to ignore a part of the pay system that consumes more than $£ 100$ m year after year in a manner that is not fair, defensible, or necessary under the terms of the new consultant contract framework. These payments also provide hard evidence contradicting the views of the negotiators that they are building a contract which is fair to all specialties and that puts the maximum possible into the basic contract

What other group of NHS staff can gain $40-95 \%$ of their basic salary as a bonus from a few friends with some seemingly ineffectual lay members present to try to see that fairness prevails? White men still come out on top, with London dominating the awards. In the latest round of distinction awards, the London north west, London north east, and London south regions, with 5216 consultants, took $£ 36000000$ while 11 other regions with 21414 consultants received $£ 79000000$

Whole time contract holders, who give most time to the NHS, are $58.5 \%$ of the 26630 consultants in England and Wales and have a $93 \%$ chance of not holding an award. Maximum part time contract holders make up $24.5 \%$ of the workforce and have an $85 \%$ chance of not holding an award. The bulk of the awards go to honorary contract holders, who give less directly in terms of clinical care to NHS patients than do other types of contract holder.

Consultants must tell the negotiators how best to use the total pot of money on offer to motivate people and stimulate new styles of working for the benefit of patients. Intensity payments, over $£ 50 \mathrm{~m}$, are available with the new contract, so why not the money 
attached to distinction awards or even discretionary point awards?

Nigel Dudley consultant in elderly medicine St James's University Hospital, Leeds LS9 7TF nigel.dudley@leedsth.nhs.uk

Correspondence. Consultants' new contract. BMJ 2002:325:99. (13 July.)

\section{... and in job planning}

EDITOR-That the contract covering the work of medical consultants remains, in essence, unchanged since the formation of the NHS in 1948 is surprising.

The contractual arrangements have been described to the health select committee as "the ineffective hand in hand with the inequitable" (John Yates); "vague and woolly" (Consumers' Association); "a conflict of interest ... a blatant invitation to mischief"(Donald Light); "an odd situation" (John Denham); and "the worst of all worlds" (BMA).

The NHS plan made it clear that modernising the NHS would require renegotiation of the working relationship between the NHS and consultant staff, including a revision of the consultant contract.

The proposed changes to the consultant contract emphasise the need to reward those who do most for the NHS. There will be little complaint about extra pay, but complaints are likely about the arrangements for ensuring that the most is done for the NHS and the way in which this is managed. The framework for change can therefore be seen as comprising rewards and measures to ensure that more is done (box).

What becomes apparent from the proposals from the NHS plan and the framework for change is that consultants are potentially being offered a sweetener to accept greater managerial and bureaucratisation of their work. The problems will be whether the management capacity of the NHS can implement and accommodate

\section{Framework for change}

Rewards

Higher starting salary

Access to clinical excellence awards

Easier access to threshold awards

Measures to ensure more is done for the NHS

Restriction on private practice for up to seven years

Phased careers to enable more experienced doctors to become leaders and free up spaces for new consultants

New system of mandatory job planning supported by changes in the appraisal system, drawn up between doctors and management to ensure more effective use of consultant time

Specific detailing of job content, including hours of commitment to clinical work, teaching, and research these changes, whether medical compliance will be obtained, and whether resistance can be minimised. This is particularly so for job planning.

Some crucial problems for management will be whether it will be able to meaningfully penetrate medical work to develop and appraise job plans, whether managerial expertise in medical work will be sufficient to assess whether work objectives are complete, and whether managerial-medical relations will be capable of facilitating change.

The proposed changes show that there will be a close proximity and potential overlap between consultant appraisal and the contractual changes. Thus considerable medical rather than managerial leadership is needed to make any change happen. Thus the future for consultant contracts may lie in greater medical control in ensuring that job plans are meaningful and relevant and that their appraisal reflects medical understanding of consultant work.

Justin J Waring research student

School of Sociology and Social Policy, University of Nottingham NG7 2RD

ij_waring@hotmail.com

\section{Telephone use in primary care}

\section{Programme to shape demand has been} started in several practices

EDITOR-Toon's editorial on using telephones in primary care raises several points, in particular the diversity of opinion about the relative merits of clinical skill versus computer algorithms. ${ }^{1}$ He may be unaware of some primary care activity that is moving events on.

The primary care collaborative, run by the National Primary Care Development Team, aims to improve access to primary care as one of its three principal objectives. The method advocated is "advanced access," and a key element of this is the need to shape demand. This can be done by telephone consultation. Telephones can be used for managing same day demand, follow up appointments, and other queries in the same way that was used in the practice that Toon looked at.

The practices track their own data, but collectively we believe that there is a $30-50 \%$ reduction in the need for face to face consultation as a result of telephone management of same day demand, and a $15-20 \%$ reduction in the need for follow up consultations. These figures are in line with those reported for telephone consultation by Jiwa et al. ${ }^{2}$ Not only are patients more satisfied but they feel less need to book to see their general practitioner if they know that access is easier.

Around 1000 practices covering seven million patients have now been involved in the first phase of the primary care collaborative. By the end of this year we should have practices involved in every primary care trust. The government sponsors and has been most supportive of the programme.
Finally, telephone consultation is only one means of shaping demand; email consultations, expert patients (particularly those with chronic illness), and skill mix are also increasingly used solutions.

John Oldham head

National Primary Care Development Team,

Manchester M60 7LP

katie.bowden@manchester.nwest.nhs.uk

1 Toon P. Using telephones in primary care BMJ 2002:324:1230-1. (25 May.)

2 Jiwa M, Mathers N, Campbell M. The effect of GP 2 Jiwa M, Mathers N, Campbell M. The effect of GP
telephone triage on numbers seeking same-day appointtelephone triage on numbers seekin
ments. Br J Gen Pract 2002;52:390-1.

\section{Telephones have proved useful in managing cystic fibrosis}

EDIToR-Toon raises the question of telephone consultation for education and monitoring of chronic diseases. ${ }^{1}$ Cystic fibrosis is one of the most problematic chronic diseases, and information regarding telephone consultation is scanty, mainly covering neonatal screening procedures and genetic counselling..$^{2-4}$

Altogether 160 patients (mean (SD) age 16.2 (10.75) years; median 14 , range $1-49$ ) are currently treated at the Tuscan referral centre, where it was decided to reserve a time for telephone consultation. We received 1081 calls (daily average 5.14) over seven months. The calls were recorded and notes made of the personal data of the patient, the time and day of the week, the member of hospital staff the call was addressed to, the reason for the call, and the correlation between the patient's clinical conditions and the number of calls.

Two hundred (18.5\%) telephone requests regarded patients aged $0-6,217$ $(20.1 \%)$ patients aged $7-12$, and $238(22 \%)$ patients aged 13-18, and 426 (39.4\%) were from adult patients. Most calls (295 (27.3\%)) were received on Mondays and Thursdays (226 (20.9\%)). Only $357(33 \%)$ calls took place in the specified time slot. The calls were directed to doctors in $938(86.8 \%)$ cases.

The calls mainly concerned aspects of patients' medical care: 285 (26.4\%) were to request test results, $252(23.3 \%)$ were to request information about medical treatment, $225(20.8 \%)$ were due to a worsening clinical condition, $77(7.1 \%)$ were to discuss the situation with the family doctor, $75(6.9 \%)$ were to fix appointments, $59(5.5 \%)$ were to ask for drug prescriptions, $15(1.4 \%)$ were to ask for explanations of medical treatment, $8(0.8 \%)$ were to ask for medical certificates, and $85(7.8 \%)$ were for other reasons. A negative correlation $(r=$ $-0.52, \mathrm{P}<0.05)$ was found between lung function (measured as forced expiratory volume in one second) and number of phone calls.

Telephone consultations are an important part of the management of cystic fibrosis. ${ }^{5}$ They helped patients and their families to save time and costs, although we need to quantify better both the limits and the benefits for health professionals. This service has improved the quality of management of cystic fibrosis, although it has been impossi- 
ble to calculate whether these calls reduced the number of appointments. The Italian health system would do well to investigate the possibilities of managing chronic diseases effectively by using telephone consultation and thereby reducing pressure on medical staff and saving them valuable time. Giovanni Taccetti paediatrician, Cystic Fibrosis Centre

g.taccetti@meyer.it

Filippo Festini cystic fibrosis nurse specialist, Cystic Fibrosis Centre

Maurizio de Martino full professor of paediatrics Department of Paediatrics, University of Florence, Anna Meyer Children's Hospital, 50132 Florence, Italy

1 Toon P. Using telephones in primary care. BMJ 2002;324:1230-1. (25 May) Philadelphia: Lippincott Williams and Wilkins, 2000. Genetic counseling and neonatal screening for cystic Pediatrics 2001;107:699-705.

4 Tluczek A, Mischler EH, Farrell PM, Fost N, Peterson NM, Carey P, et al. Parents' knowledge of neonatal screening and response to false-positive cystic fibrosis testing $J$ Dev Behav Pediatr 1992;13:181-6.

5 Boyle MP, Farukhi Z, Nosky ML. Strategies for improving Boyle Mr, Faruki Z, Nosky ML. Strategies for improving parent view. Pediatr Pulmonol 2001;32:428-36.

\section{Discussion of risk pervades doctor-patient communication}

EDITOR-Edwards et al neatly summarised the state of current knowledge on communicating risk. ${ }^{1} \mathrm{I}$ have three further points to add.

Firstly, readers may be interested in the risk ladder we developed to display the risks with some everyday risks (figure)..$^{23}$

Secondly, I think that the authors either have chosen not to address or been unaware that communication about risk and safety takes place throughout a consultation and not simply when the conversation turns specifically to that issue. Likewise, in written materials, it is located not only in
2 Orenstein DM, Rosenstein BJ, Stern RC. Cystic fibrosis.

3 Ciske DJ, Haaviso A, Laxova A, Rock LZ, Farrell PM. fibrosis: an assessment of the communication process. associated with anaesthesia in comparison

the section describing risks but throughout the whole document. My experience with the Royal College of Anaesthetists' patient information project has shown me that patient information is not simply about putting facts down on paper. Rather, it throws the entire implied relationship between clinician and patient into focus and nowhere is this better seen than in the related issues of safety and risk. The choice of words and the professional self image doctors project may be more powerful influences on patients' decisions than precise numerical estimates of risk or their visual analogues. Take, for example, the following text, typical of a preoperative leaflet about anaesthesia:

"Q: What happens once I am asleep?

"A: You are never left alone during an operation. Your anaesthetist stays with you and keeps you safe, pain free, and unaware of what is going on. Drugs are constantly being given to you throughout the operation to make sure you are kept safe."

In this example, a question, which could simply be one of curiosity, is used as an opportunity both for reassurance and also possibly for education about the role of anaesthetists in general. The answer mentions safety, although the question does not. Is the writer of the booklet justified in assuming that patients regard anaesthesia as being so risky that an answer to a simple question about procedure can be expected to allude to safety as a matter of course?

For the patient who had not considered that anaesthesia might be risky would this be a disconcerting change of tone? Furthermore, if safety is an issue, what do patients need to be kept safe from? The excesses of the surgeon? The undesired effects of the anaesthetic? Electrical, infectious, or other hazards? Without qualification, "safe" is not only meaningless but may actually provoke anxiety. The analysis could continue further, but I have made my point.

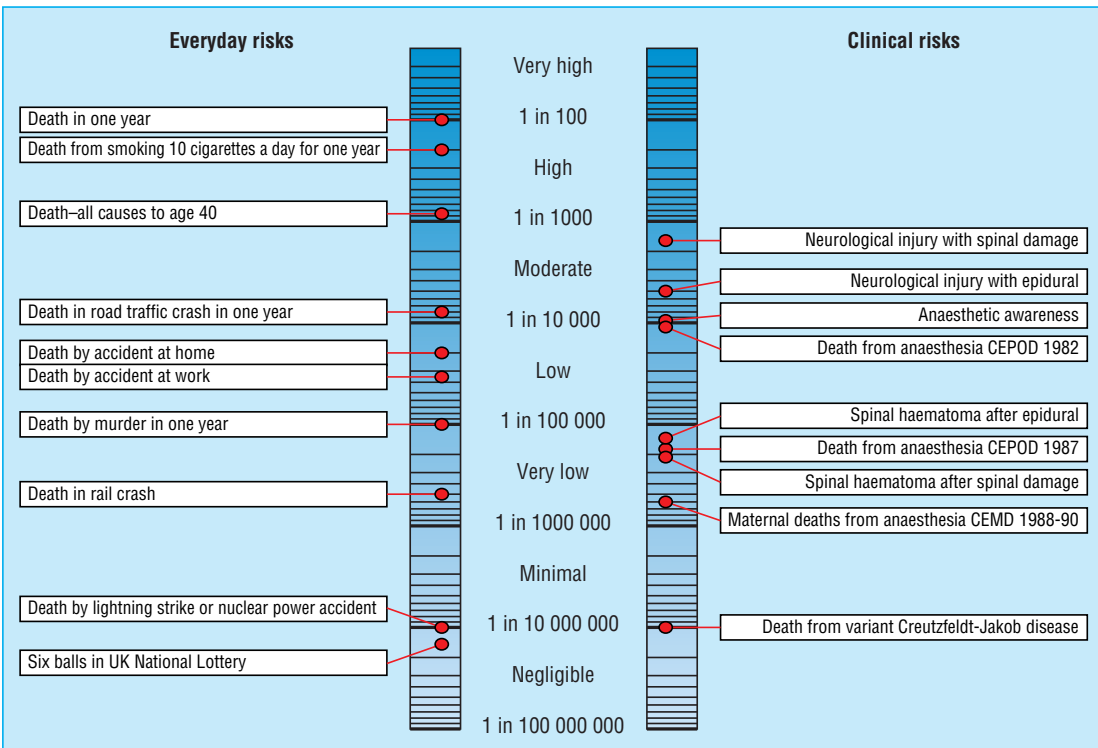

Risk ladders for everyday and clinical risks. Reproduced with permission of Blackwell Scientific ${ }^{2}$
Finally, risks must be considered, and the fact that doctors lack reliable data for many risks is a cause for concern. More sobering still is the thought that doctors are still waiting for reliable evidence of benefit for many healthcare interventions.

Andrew F Smith consultant anaesthetist Royal Lancaster Infirmary, Lancaster LA1 4RP Andrew.Smith@l.bay-tr.nwest.nhs.uk

1 Edwards A, Elwyn G, Mulley A. Explaining risks: turnin numerical data into meaningful pictures. BMJ 2002;324:827-30. (6 April)

2 Adams AM, Smith AF. Risk perception and communication: recent developments and implications for anaesthesia. Anaesthesia 2001;56:745-55.

3 Adams AM, Smith AF. Probability of winning the National Lottery-a reply. Anaesthesia 2002;57:186-7. (revised version of ladder).

4 Smith R. Where is the wisdom? The poverty of medical evidence. BMJ 1991;303:798-9.

\section{Stress and breast cancer}

\section{Basic error may have occurred}

EDItor-One of the main findings of the paper by Graham et al was that women who had had one or more severely stressful life experiences in the five years after diagnosis had a lower risk of recurrence than those who didn't (hazard ratio 0.52). ${ }^{1}$ Using information collected after baseline (diagnosis in this study) in a survival model is fraught with difficulty because collection of that information may not be possible after the event of interest has occurred. Careful interpretation of the results of any such analysis is therefore recommended.

It seems that a mistake in interpretation has occurred in this paper. Women who had a recurrence were not interviewed again more than eight weeks after their recurrence. So, for example, a woman in whom cancer recurred after 12 months would have nearly four years of missing data for the variable "severely stressful life experiences." It follows that the investigators were more likely to detect stressful life experiences in women who had recurrences later on in the study or not at all. The finding that stressful life experiences were associated with a decreased incidence of recurrence is probably due to this ascertainment bias rather than any real effect.

Tony Brady senior statistician

Intensive Care National Audit and Research Centre, London WC1H 9HR tony@icnarc.org

1 Graham J, Ramirez A, Love S, Richards M, Burgess C. Stressful life experiences and risk of relapse of breast cancer: observational cohort study. BMJ 2002;324:1420-2. (15 June.)

\section{Authors' reply}

EDITOR-The main finding of our paper was that women who experienced one or more severely stressful life events did not have a higher risk of recurrence of their disease than women not experiencing such events. That their risk was in fact lower was, as we describe in the paper, a marginal finding for which we can provide no clear explanation. 
Brady says that the lack of a relation between experiencing one or more severely stressful life events and recurrence may be due to using data known before baseline and also that it may have arisen due to ascertainment bias. We have avoided the former and adjusted for the latter as far as possible through the statistics we used in our analysis, which are detailed in the online version of the paper, but not the paper version. Specifically, since severely stressful life experiences and episodes of depression could occur at any time over the study period, these variables formed time dependent covariates in the Cox proportional hazards model. With this method, the time dependent hazard ratio quoted is a comparison of when a patient is experiencing a severe life event to when they are clear of severe life events. Hence those with longer follow up provide more data, but would only aid the prediction of a relapse if there was a relation between severe life event and relapse.

Jill Graham health psychologist

Cancer Research UK London Psychosocial Group, Adamson Centre, St Thomas's Hospital, London

SE1 7EH

jill.graham@kcl.ac.uk

Sharon Love medical statistician

Imperial Cancer Research Fund Medical Statistics Group, Centre for Statistics in Medicine, Institute of Health Sciences, Oxford OX3 7LF

Amanda Ramirez professor of liaison psychiatry Cancer Research UK London Psychosocial Group

\section{Genetic testing for familial Alzheimer's must be debated}

EDITOR-Rigg's news item about genetic testing for familial Alzheimer's disease in a Spanish hospital highlights the need to extend the current debate in the Spanish press to the scientific community. In spite of its high genetic penetrance, environmental factors can also determine the phenotypic presentation of familial Alzheimer's disease. ${ }^{2}$ Since the disease is currently incurable and no interventions have been proved to either prevent or delay the onset of the disease, considerations of the quality of life of future patients are paramount.

People who have been told their prognosis are faced with psychological problems that may be helped by regular counselling or psychological support, although neither the effectiveness of these interventions nor their long term effects have yet been shown. ${ }^{3}$ They have to live with the psychological effects (which in some cases have led to suicide) even though an effective treatment may have been developed or they may have died of something else by the time Alzheimer's disease occurs some 15,20 , or even 30 years later.

Relationships and life plans may be influenced substantially by the diagnosis. Should affected people inform future partners that they have this genetic mutation and may need full time care in the future? If they want children should the embryo undergo genetic selection?
The social system is currently not prepared to provide support to these new patients in finding employment suitable to a working lifestyle that will be different from that of someone without the mutation. In addition, social security benefits do not take into account the future costs generated by the diagnosis (such as days off work). Insurance companies are unlikely to accept a person with a certain future disability, and if they did it would be at a high cost.

The patient could be invited to participate in studies of developing experimental preventive treatments that would entail them being subjected to various diagnostic tests and in taking drugs in clinical trials. Although patients would be very motivated to try to improve their future prognosis, the cost in terms of quality of life-for example, from side effects-may none the less be high.

Genetic testing could lead to a whole series of circumstances that may have a negative effect on the quality of life of people testing positive. Early diagnosis of the disease might unleash a process of premature medicalisation. The scientific community has already been called on to ensure that genetic technologies take social, ethical, and other aspects of quality of life into account and be based on evidence. Maybe we should ask whether we are trying to treat non-existent patients.

Josep M Garcia registered nurse

Corporacio Parc Taulí, E-08202 Sabadell,

Barcelona, Spain

(josepmgarcia@hotmail.com)

José Luis R Martín researcher

Hospital de la Santa Creu I Sant Pau, E-08025

Barcelona

1 Rigg P. Spanish hospital offers genetic test for familial Alzheimer's. BMJ 2002;324:1478. (22 June.)

2 Lippa CF, Swearer JM, Kane KJ, Nochlin D, Bird TD, Ghetti B, et al. Familial Alzheimer's disease: site of mutation influences clinical phenotype. Ann Neurol 2000; 48:376-9.

3 Broadstock M, Michie S, Marteau T. Psychological consequences of predictive genetic testing: a systematic review. Eur J Hum Genet 2000;8:731-8.

4 Verlinsky Y, Rechitsky S, Verlinsky O, Masciangelo Ch, Lederer K, Kuliev A. Preimplantation diagnosis for early-onset Alzheimer disease caused by V717L mutation. JAMA 2002;287:1018-21.

5 Melzer D, Zimmern R. Genetics and medicalisation. $B M$ 2002:324:863-4.

\section{Postmortem radiology is useful but no substitute for necropsy}

EDITOR-Recent high profile events surrounding postmortem examination procedures have required that additional means of examination be sought. ${ }^{1}$ A necropsy describes a variety of methods used to ascertain the cause of death or pathological conditions within a deceased person, and ranges from a needle biopsy to radiology. Common usage of the term, however, refers to the thorough macroscopic and microscopic examinations of the organ systems, which are evidence based and derived from the centuries of research into pathological processes and their correlation with premorbid conditions. Information from the necropsy aids examiners to complete a medical certificate of cause of death to the best of their knowledge and belief, as instructed by law. ${ }^{2}$

Postmortem radiology is a useful tool to confirm the presence of diseases, but it should not be used to replace the gold standard examination, a necropsy. ${ }^{3}$ Bisset et al in their paper often do not confirm their diagnoses through this gold standard; diagnoses where they are used show a difference of importance placed by the pathologist as to the cause of death. It should also be noted that most diagnoses provided by imaging are in fact "modes of death" and as such, if left unqualified by an underlying causation, are unacceptable on a death certificate. ${ }^{4}$ This error may result in referral of the case by the registrar general to the coroner for further investigation, which may cause further upset for the next of kin. ${ }^{2}$

The difficulty in interpretation of images obtained by magnetic resonance scanning is well recognised in pathology, with anecdotal evidence of diagnostic inaccuracies discovered when examining subsequent surgical specimens or at necropsy. Postmortem artefacts, recognisable to the pathologist, also remain to be thoroughly documented radiologically.

The political problems also require addressing should it become apparent that cadavers are undergoing imaging when waiting lists continue to increase. Even though the work is performed out of hours, or in private facilities, it may result in embarrassment for local health authorities.

The necropsy in itself is comparatively inexpensive and may provide accurate information based on histology, microbiology, and toxicology-tests that are beyond the reach of magnetic resonance imaging. Histological and microbiological results are essential for the creation of health statistics that form the basis of future healthcare provision. Would postmortem radiology alone allow identification of the type of tumour or the infectious causation? As such, surely doctors are failing to identify the cause of death "to the best of their knowledge and belief."

Benjamin Swift specialist registrar

Department of Histopathology, Level 3, Sandringham Building, Leicester Royal Infirmary, Leicester LE1 5WW

bs7@le.ac.uk

1 Bisset RAL, Thomas NB, Turnball IW, Lee S. Postmortem examinations using magnetic resonance imaging: four year review of a working service. BMJ 2002;324:1423-4 (15 June.)

2 Swift B, West K. Death certification: an audit of practice entering the 21st century. J Clin Pathol 2002;55:275-9.

3 Huisman TA, Wisser J, Stallmach T, Krestin GP, Huch R, Huisman TA, Wisser J, Stallmach T, Krestin GP, Huch R,
Kubik-Huch RA. MR autopsy in fetuses. Fetal Diagn Ther Kubik-Huch RA.

4 Registrar General. Medical certificate of cause of death (form 66): notes for doctors. London: Office for National Statistics.

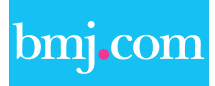

\section{Rapid responses}

Correspondence submitted electronically

is available on our website 